\title{
Reirradiation Opportunities of Cancer Patients in a Developing Country
}

\author{
Elvisa Kozma ${ }^{1}$, Agim Sallaku ${ }^{2}$ \\ University Hospital Mother Theresa, Service of Oncology, Tirana, Albania
}

\begin{abstract}
Purpose: The aim of this study is to show reirradiation possibilities of cancer patients in a developing country like Albania. Methods and Materials: From 2012 until 2015 we have reirradiated 72 patients, 42 with local and/or regional recurrence from head and neck and rectal cancer and 30 with bone metastasis from different primary tumors. Median age of patients was 56 years (28-72years). Thirty three patients were treated with a Cobalt 60 machine and thirty nine with aLinear Accelerator of 6 and 18 MV energy. They had a Karnofsky Performance State of 50-90\% and none of them could be treated surgically. We used different types of fractionations depending from the case (standard fractionation, hyperfractionation or hypofractionation). Time of reirradiation was not less than 6 months from the first radiotherapy treatment and the dose varied from 8-40Gy. Results: All patients tolerated treatment. Acute toxicities were tolerable and present in $100 \%$ and $30 \%$ of head and neck and rectal cancer patients respectively and 10\% of patients with bone metastasis. Chronic toxicities were acceptable. One patient had a rectal-cutaneous fistula and another demonstrated signs of subocclusion 3 months after reirradiation but without necessary for intervention. At two months follow up, pain relief was seen in 86.4\% and $95 \%$ of head and neck and rectal cancer patients respectively and $97 \%$ of patients with bone metastasis. Anyway these percentages deteriorated over the months. Conclusions: Reirradiation of patients with in-field recurrence is a feasible treatment also in developing countries. It shows improvements of quality of life with acceptable toxicity. Implementation of new and more precision devices will give us the possibility to use higher reirradiation doses with the purpose of a better local control and survival.
\end{abstract}

Keywords: Reirradiation, head and neck cancer, rectal cancer, bone metastasis, toxicity, quality of life

\section{Introduction}

During the latest years, improvements inthe treatment of cancer patients had a positive impact on overall survival.But, nevertheless a considerable number of this category of patients still suffersfrom local and/or regional recurrence. Many of them present tumor recurrences that are inoperable and reirradiation alone or concurrent with chemotherapy is the only chance of treatment with radical or palliative purpose. Radiation oncologists based on preclinical and clinicaldatawhich haveshown that a variety of normal tissues can berecoveredfrom occult radiation injury, have been encouragedto evaluate the possibilities of reirradiation, it's benefits and risk factors and differentreirradiation regimens(1,2).Although till now no data have clearly demonstrate that recurrent tumors are less radiosensitive, the benefit from retreatment is known to be related with the tumor burden, observed toxicities from previous irradiation and patient's performance state. (3).Even so, the decision making on whether to reirradiate a patient or not is complex and still remains a challenging problem. The aim of this study is to show the possibilities of reirradiation in a developing country.

\section{Methods and Materials}

From 2012 until 2015 we have reirradiated 72 patients, 22 with head and neck cancer, 20 with rectal cancer and 30 with bone metastasis from different primary tumors. All patients had undergone multimodality treatment before and had a Karnofsky Performance State of 50-90\%.They had a median age of 56 years (28-72years)and the most common complaint for all of them was pain. Except one patient who had visceral metastasis and them with bone metastasis all others have only local and/or regional recurrence. The multidisciplinary team had decided that none of them was

candidate for surgery and the only choice of treatment was reirradiation in concomitance or not with chemotherapy. Thirty nine patients were reirradiated with a Linear Accelerator of 6 and $18 \mathrm{MV}$ energy, and thirty three with a Cobalt 60 machine. The median interval between two irradiations was 21 months (6-80 months).All patients with recurrent rectal cancer were reirradiated in concomitance with chemotherapy (Xeloda $825 \mathrm{mg} / \mathrm{m}^{2}$ ).Meanwhile, except two all other head and neck cancer patients were also retreated with concomitant radio-chemotherapy (chemotherapy was weekly Cisplatin $40 \mathrm{mg} / \mathrm{m}^{2}$ ). We used three different types of fractionations depending from the case (Tab1). The dose of first irradiation ranged from 30$66 \mathrm{~Gy}$ and of reirradiation from 8-40Gy. All patients were followed up prospectively through clinical visits, blood checks, disease specific markers and radiologic imaging. Itvaried from 1 to 35 months. During the first year follow up was every two months and we evaluatedquality of life, local control, acute and late toxicitiesbased on Radiation Therapy Oncology Group scoring system.Serious toxicity was defined as more than grade 3 .

Table 1: Patient's characteristics

\begin{tabular}{|l|l|}
\hline \multicolumn{1}{|c|}{ Characteristic } & $\begin{array}{c}\text { Number } \\
\text { of patients }\end{array}$ \\
\hline Age & \\
Median & 56 \\
Range & $28-72 \mathrm{yr}$ \\
\hline Gender & 32 \\
Female & 40 \\
Male & \\
\hline Type of tumor & 22 \\
Head and neck & 20 \\
Rectal & 30 \\
Bone metastasis from different primaries & \\
\hline Time between two RT treatments & 21 \\
Median interval & $6-80 \mathrm{~m}$ \\
Range &
\end{tabular}

Volume 5 Issue 5, May 2016 www.ijsr.net 
International Journal of Science and Research (IJSR)

ISSN (Online): 2319-7064

Index Copernicus Value (2013): 6.14 | Impact Factor (2015): 6.391

\begin{tabular}{|l|l|}
\hline Radiation regimen & 3 \\
Normal fractionation (2Gy/day) & 39 \\
Hyperfractionation (2x1.25Gy/day) & 30 \\
Hypofractionation (8, 20 or 30Gy/day) & \\
\hline Concurrent chemotherapy & 40 \\
Yes & 32 \\
No & \\
\hline
\end{tabular}

\section{Results}

All patients tolerated treatment and finished it in time without interruptions. After 2 months pain relief was seen in $86.4 \%$ and $95 \%$ of head and neck and rectal cancer patients respectively and $97 \%$ of patients with bone metastasis from different primary tumors. The evaluation of pain was done based on patient self- assessments using a numerical rating score from 0 (no pain) to 10 (worst imaginable pain). Also every change in pain medication during follow-up was recorded. The evaluation showed that $44 \%$ of all patients had complete pain relief, $49 \%$ had partial pain relief and $7 \%$ no response. Patients who had complete or partial response had no need to use strong opioids until progression of disease. Rectal bleeding and gastrointestinal disorders were disappeared. Acute toxicities were tolerable. They are shown in tab. 2 for each category of patients.

Table 2: Acute toxicitiesof retreated cancer patients

\begin{tabular}{|l|l|l|l|l|l|l|l|}
\hline \multicolumn{4}{|c}{ Head and neck tumors } & \multicolumn{2}{c|}{ Rectal cancer } & \multicolumn{2}{c|}{ Bone metastasis from different primaries } \\
\hline & Oral mucositis & Radiodermatitis & Dysphagia & Diarrhea & Cystitis & Diarrhea & Dysphagia \\
\hline G1 & $\mathbf{2 7 \%}$ & $\mathbf{4 1 \%}$ & $\mathbf{2 7 \%}$ & - & - & $\mathbf{1 0 \%}$ & $\mathbf{1 3 \%}$ \\
\hline G2 & $\mathbf{6 4 \%}$ & $\mathbf{5 4 . 5 \%}$ & $\mathbf{5 9 \%}$ & $\mathbf{3 0 \%}$ & $\mathbf{3 0 \%}$ & - & - \\
\hline G3 & $\mathbf{9 \%}$ & - & $\mathbf{1 4 \%}$ & - & - & - & - \\
\hline G4 & - & - & - & - & - & - & - \\
\hline
\end{tabular}

Chronic toxicities consisted in deterioration of existed xerostomiafrom G2 to G3 in 3 head and neck cancer patients and skin fibrosis in 5 patients. One rectal cancer patient demonstrated signs of subocclusion 3 months after reirradiation but without need for surgery and another had a rectal-cutaneous fistula. No one showed any neurologic abnormalities affecting motor or sensory function. They were all able to walk and were continent for urine and stool until the time of death. None of reirradiated patients risked their life as a result of toxicity, nevertheless many of them didn't live enough to have an exact evaluation of late toxicity. Over the months pain control deteriorated and at 2 years follow up only one of the surviving patients was free of pain.

\section{Discussion}

In the past cancer patients were irradiated only once. The tolerance doses were known only for one radiotherapy treatment and radiation oncologists were very reserved about reirradiation as a result of possible toxicities. Nowadays it is not more a taboo since an increasing number of publications have shown benefits of reirradiation with acceptable toxicity (4). However, as it is associated with an increased risk of acute and late toxicitiesit is very important before taking the decision to balance between the benefits and risks of retreatment for every case. Prediction of individual toxicity risk will help in the future towards a personalized treatment(5,6).In our study we evaluated the role of reirradiation in improving the quality of life in cancer patients with progressed disease and noted an improvement of it in more than $85 \%$ of retreated patients. This is encouraging to indicate retreatment even though with palliative purpose. The category of patients we treated had a limited survival so improving quality of life was of high relevance. Also a study which surveys the use of reirradiation for in-field failures after previous radiation treatment with radical purpose among Canadian radiation oncologists showed that one of the major indications for offering retreatment was to improve quality of life (7). Surgery with curative purpose is an important determinant for the outcome of patients with cancer $(8,9)$ and it should be recommended in every case when possible. None of our patients was candidate for surgery as a result of locally advanced recurrence. This had its negative impact onlocal control and overall survival. Reirradiation alone or concurrent with chemotherapy was the only possible treatment. It was tolerated from all the patients with only a small number of head and neck tumor patients demonstrating G3 toxicities. Also chronic toxicities seen in few patients were not life threatening. This may be in part due to the radiotherapy doses and type of fractionation we used. Just based on the existing data with the purpose to have a local control with less side effects we used hyperfractionation regimen twice daily, with a minimum distance of 6 hours between two fractions, to reirradiate head and neck and rectal cancer patients $(10,11)$. Whereas in patients with bone metastasis we used hypofractionation (single dose or multifractionated regimen conditioned by the first dose of irradiation,patient's conditions and their life expectancy). Patients with a poor expected survival benefit from a shorter course of reirradiation because it meant less daily trips to the radiotherapy department, positioning on the treatment couch and also less costs for the retreatment(12). Since the risk of causing myelopathy after reirradiation is higher due tothe higher cumulative dose to spinal cord $(13,14)$,we tried to avoid it based on the risk scoreanalyzed by Nieder et al(three variables: cumulative biological dose BED $\leq 135.5 \mathrm{~Gy}_{2}$, BED of each single radiotherapy course $\leq 98 \mathrm{~Gy}_{2}$, and interval between the coursesnot shorter than 6 months) (15).According to Nieder's risk categories the majority of our reirradiated patients had an estimated low risk of radiation induced myelopathy and indeed no one of them developed myelopathy. So our data supportsreirradiation of patients with pain from bone metastasis, especially after response from first treatment. The three types of fractionation we used (single dose 8Gy, 5x4Gy and 10x3Gy) were safe and effective for pain relief. Albania as a developing country has restricted possibilities for the latest advanced radiotherapy devices, which enable higher total reirradiation dose to the target with less toxicityin normal tissues and better local 


\section{International Journal of Science and Research (IJSR) \\ ISSN (Online): 2319-7064 \\ Index Copernicus Value (2013): 6.14 | Impact Factor (2015): 6.391}

control and overall survival. In the future we hopeit could be possible. Alsowe emphasize thecarefulpatient's selection and their treatment in specialized centers.

\section{Conclusions}

Our study demonstrated that also in developing countries reirradiation is a possible option of treatment for patients with in field recurrence. It improves quality of life with acceptable side effects. However we should take into account that we treated a small number of patients from which clear conclusions cannot be drawn. Prospective randomized studies should be planned in the future to decide the optimal fractionation and total reirradiation dose to the tumor with less side effects in normal tissues. Installation of new and more advanced radiotherapy machines in our department will give patients the opportunity for a curative treatment with a better local control and overall survival.
[14] Van den Hout WB, Van der Linden YM, Steenland E, et al. Single- versus multiple-fraction radiotherapy in patients with painful bone metastases: Cost-utility analysis based on a randomized trial. J Natl Cancer Inst 2003;95:222-229

[15] Wong CS, Van Dyk J, Milosevic M, Laperriere NJ, Radiation myelopathy following single courses of radiotherapy and retreatment. Int $\mathbf{J}$ Radiat Oncol Biol Phys 1994;30:575-81

[16] Maranzano E, Bellavita R, Floridi P, Radiation-induced myelopathy in long-term metastatic spinal cord compression patients after hypofractionated radiotherapy: a clinical and magnetic resonance imaging analysis. Radiother Oncol 2001;60:281-8.

[17] Nieder C, Grosu AL, Andratschke NH,Molls M, Update of human spinal cord reirradiation tolerance based on additional data from 38 patients. Int J Radiat Oncol Biol Phys 2006; 66, 5,1446-1449

\section{Reference}

[1] Lavey RS, Taylor J, Tward JD et al, The extent, timecourse, and fraction size dependence of mouse spinal cordrecovery from radiation injury. Int J Radiat Oncol Biol Phys.1994;30:609-617

[2] Ang KK, Jiang GL, Feng Y, et al. Extent and kinetics of recovery of occult spinal cord injury. Int J Radiat Oncol BiolPhys. 2001;50:1013-1020.

[3] Lee AW, Foo W, Law SC, Reirradiation for recurrentnasopharyngeal carcinoma: factors affecting the therapeuticratio and ways for improvement. Int $\mathbf{J}$ Radiat Oncol BiolPhys. 1997; 38:43-52

[4] Kruse JJ, Stewart FA Gene expression arrays as a toolto unravel mechanisms of normal tissue radiation injury

[5] and prediction of response. World J Gastroenterol 2007 13:2669-2674

[6] Alsner J, Andreassen CN, Overgaard J. Genetic markers for prediction of normal tissue toxicity after radiotherapy. Semin Radiat Oncol. 2008 18:126-135

[7] Valdagni R, Rancati T, Fiorino C. Predictive models oftoxicity with external radiotherapy for prostate cancer:

[8] clinical issues. Cancer. 2009 115:3141-3149

[9] Joseph KJ, Al-Mandhari Z, Pervez N et al Reirradiation after radical radiation therapy: a survey of patterns of practice among Canadian Radiation Oncologists. Int J Radiat Oncol Biol Phys2008; 72,1523-1529

[10]Dresen RC, Gosens MJ, Martijn H, et al. Radical resection after IORT-containing multimodality treatment is the most important determinant for outcome in patients treated for locally recurrent rectal cancer. Ann Surg Oncol 2008;15:1937-47.

[11]Bouchard P, Efron J. Management of recurrent rectal cancer. Ann Surg Oncol 2010;17:1343-56.

[12] Das P, Delclos M, Skibber J, Rodriguez-Bigas M et al. Hyperfractionated accelerated radiotherapy for rectal cancer in patients with prior pelvic irradiation. Int $\mathbf{J}$ Radiat Oncol Biol Phys 2010; 77; 60-65

[13]Baujat B, Bourhis $\mathrm{J}$, Blanchard $\mathrm{P}$ et al. Hyperfractionated or accelerated radiotherapy for head and neck cancer.Cochrane Database Syst Rev. 2010; $8 ;(12)$ 